\title{
Automated Orthogonal Control System for Electrospray Ionization
}

\author{
Gary A. Valaskovic and James P. Murphy, III \\ New Objective, Inc., Woburn, Massachusetts, USA \\ Mike S. Lee \\ Milestone Development Services, Newtown, Pennsylvania, USA
}

\begin{abstract}
Low-flow electrospray ionization is typically a purely electrostatic method, used without supporting sheath-gas nebulization. Complex spray morphology results from a large number of possible spray emission modes. Spray morphology may assume the optimal Taylor cone-jet spray mode under equilibrium conditions. When coupling to nanobore gradient elution chromatography, however, stability of the Taylor cone-jet spray mode is compromised by the gradient of mobile phase physiochemical properties. The common spray modes for aqueous/ organic mobile phases were characterized using orthogonal (strobed illumination) transmitted light and (continuous illumination) scattered light imaging. Correlation of image sets from these complementary illumination methods provides the basis for spray mode identification using qualitative and quantitative image analysis. An automated feedback-controlled electrospray source was developed on a computer capable of controlling electrospray potential using an image-processing based algorithm for spray mode identification. The implementation of the feedback loop results in a system that is both self-starting and self-tuning for a specific spray mode or modes. Thus, changes in mobile phase composition and/or flow rate are compensated in real-time and the source is maintained in the cone-jet or pulsed cone-jet spray modes. (J Am Soc Mass Spectrom 2004, 15, 1201-1215) (C) 2004 American Society for Mass Spectrometry
\end{abstract}

S ince the late 1980s, electrospray ionization mass spectrometry (ESI-MS) has become a central tool in the life sciences. ESI-MS based methods are now routinely applied throughout drug discovery and development impacting both small molecule [1] and large molecule applications, such as proteomics [2-4]. The combination of high performance liquid chromatography with mass spectrometry (LC-MS) has been central to the widened scope of application and routine use [1]. Commercially available ESI-MS instruments suitable for coupling to $\mathrm{LC}$ at $\mathrm{mL} / \mathrm{min}$ flow rates rapidly evolved [5] based on the original $\mu \mathrm{L} / \mathrm{min}$ implementation by Fenn and coworkers [6] and the original work of Dole and coworkers [7]. The principal means of increasing the operable ESI flow rate was with the addition of either coaxial or cross flow sheath gas to aid in the droplet formation suitable for ion generation and mass analysis [8-10].

While much research and development effort was aimed at increasing electrospray's operable flow rate, a

Published online July 2, 2004

Address reprint requests to Dr. G. A. Valaskovic, New Objective, Inc., 2 Constitution Way, Woburn, MA 01801, USA. E-mail: garyv@ newobjective.com number of groups conducted studies at lower flow rates [11-14]. Early observations by Gale and Smith [11] showed that the flow rate could be reduced to 200 $\mathrm{nL} / \mathrm{min}$ without reducing the signal-to-noise $(\mathrm{S} / \mathrm{N})$ ratio. Wilm and Mann $[12,15]$ demonstrated that flow rates could be reduced another order of magnitude, to the 10 to $20 \mathrm{~nL} / \mathrm{min}$ level, with no significant reduction in S/N. At approximately the same time, Emmet and Caprioli [13] demonstrated exceptionally high sensitivity for peptide analysis by directly coupling nanobore (50-100 $\mu \mathrm{m}$ inside diameter) LC columns to low-flow (100-200 nL/min) ESI. Ultra-low flow rates of less than $1 \mathrm{~nL} / \mathrm{min}$ have been shown to yield significant ion current suitable for MS [14, 16] and enable the direct coupling of small bore $(\approx 5 \mu \mathrm{m})$ capillary electrophoresis, with sub-attomole sensitivity [17]. Collectively, these various nanoliter-per-minute ESI-MS methods have become known as nanospray.

Recent experiments suggest that operation at nanospray flow rates effect ionization on a fundamental level. Ionization effects have been observed for both off-line [18, 19] and on-line [20] nanospray methods. It is important to note that electrostatic attraction between mobile phase and counter-electrode is typically the sole source of mobile phase flow for off-line nanospray [12, 
15]. It is common practice to operate off- or on-line nanospray without the use of sheath gas. Under such conditions, the electrostatic field is the driving force for aerosol generation and droplet dispersion $[12,21]$. This situation is quite unlike conventional flow ESI, in which pneumatically assisted nebulization is the initial driving force for aerosol generation and the voltage is used to charge the droplets [22]. Both theory and experiment have established that the aerosol droplet size generated by non-assisted electrospray is a function of flow rate $[12,23]$. The smaller droplets generated by low-flow ESI appear to have a high $\mathrm{m} / \mathrm{z}$ with a diameter close to the space charge limit and offer increased ionization efficiency for mass spectrometry [12, 15]. Increased ionization efficiency is in part derived from an increase in mobile phase surface area available for population by an analyte molecule [24-26]. Consequently, the increased surface area afforded by nanospray results in an improved tolerance to salts and significantly reduced ion suppression [18-20].

The physics of spray morphology is complex. Early investigations of electrospray performed by Zeleny demonstrated that the liquid and subsequent spray emitting from the nozzle may take on a wide variety of physical forms or spray modes [27, 28]. The specific spray mode is highly dependent on the geometry of the emitter, the strength and shape of the electric field, flow rate, and physiochemical characteristics of the mobile phase $[22,29-31]$. These spray modes generate droplets of differing size and charge distribution [31-33]; furthermore, many spray modes exhibit pulsing characteristics in which droplet characteristics periodically vary $[30,34,35]$. Ten of the most commonly observed spray modes have been defined by Jaworek [29], following on the work of Cloupeau [22]. Perhaps the most effective spray mode for producing droplets suitable for ESI-MS is the cone-jet spray mode [36] in which a stable, non-pulsating Taylor cone is formed [23, 32, 37].

A stable cone-jet spray mode is perturbed by gradient elution chromatography since mobile phase characteristics such as surface tension and viscosity change during the experiment. Compromises are often made, such as the addition of sheath gas, or operation at higher than optimal voltage. The cone-jet spray mode is an equilibrium condition with a balance between opposing cohesive forces (i.e., surface tension) and electrostatic repulsion [36], also referred to as a balance between electrostatic and capillary pressure [22]. One set of ESI tuning conditions (voltage, inlet distance, flow rate etc.) is unlikely to yield a stable cone-jet spray mode throughout the LC gradient. In theory, it would be advantageous to control spray mode for the desirable cone-jet geometry throughout an LC-MS experiment.

Here we demonstrate an optoelectronic system for the implementation of a self-tuning and self-adjusting ESI source. Optical channels of information, obtained from both imaging (charge coupled device [CCD]) and non-imaging (photodiode) detectors, are positioned or- thogonal to the spray axis of a nanospray emitter. These optical channels are used to characterize the spray mode, independent of spray- or ion-current. The imaging channel uses a spray visualization system in which an image acquisition and analysis computer determines the spray mode through direct empirical characterization of the spray image. This system forms the core of a feedback loop in which a control algorithm adjusts applied voltage so that desirable spray modes can be obtained and maintained throughout the chromatographic analysis. The non-imaging channel provides frequency and waveform information to probe (pulsed) spray dynamics using a laser and photodiode positioned orthogonally to both the visualization and spray axis. This orthogonal control system is capable of responding to changes in flow rate and mobile phase composition.

\section{Experimental}

\section{Reagents}

HPLC grade methanol, acetonitrile (ACN), formic acid, and glacial acetic acid were obtained from Aldrich Chemical (St. Louis, MO). HPLC Grade water was obtained from Burdick and Jackson (Muskegon, MI). A standard sample of five different angiotensin peptide variants (Michrom Bioresources, Auburn, CA) was prepared in 10 and $70 \%$ ACN with $0.1 \%$ formic acid at a concentration of $50 \mathrm{nM}$ per peptide.

\section{Mobile Phase Delivery}

Mobile phase was delivered from either a precision syringe pump (Model PHD, Harvard Apparatus, Holliston, MA) using a $50 \mu \mathrm{L}$ gastight syringe (Hamilton, Reno, NV) or a split flow gradient HPLC pump. The output of a binary gradient capillary HPLC (1100 Capillary LC, Agilent, Wilmington, DE) was fed through a T-based flow splitter [38] for an approximate 10:1 reduction of flow rate. The HPLC was adjustable so that the through-tip flow rate was between 200 to 500 $\mathrm{nL} / \mathrm{min}$ for $50 \% \mathrm{ACN}$. Mobile phase A and B were 0 and $99.9 \%$ organic (either ACN or methanol) respectively, with $0.1 \%$ formic acid. The flow rate was verified by measuring the volume of mobile phase collected at the tip using a calibrated $5 \mu \mathrm{L}$ glass capillary (Drummond Scientific, Bromall, PA) for a fixed time period.

\section{Orthogonal Imaging System}

A nanospray ESI source, model PV-300-Q (New Objective, Woburn, MA) was mounted on a 2 feet $\times 3$ feet optical breadboard (Thorlabs, Newton, NJ). The breadboard was mounted on SLM-1A isolation pads (Newport, Pasadena, CA) for mechanical isolation. The nanospray source was configured to use $360 \mu \mathrm{m}$ o.d. fusedsilica ESI emitters (New Objective) having tip i.d. ranging from 5 to $30 \mu \mathrm{m}$. The ESI voltage was applied 


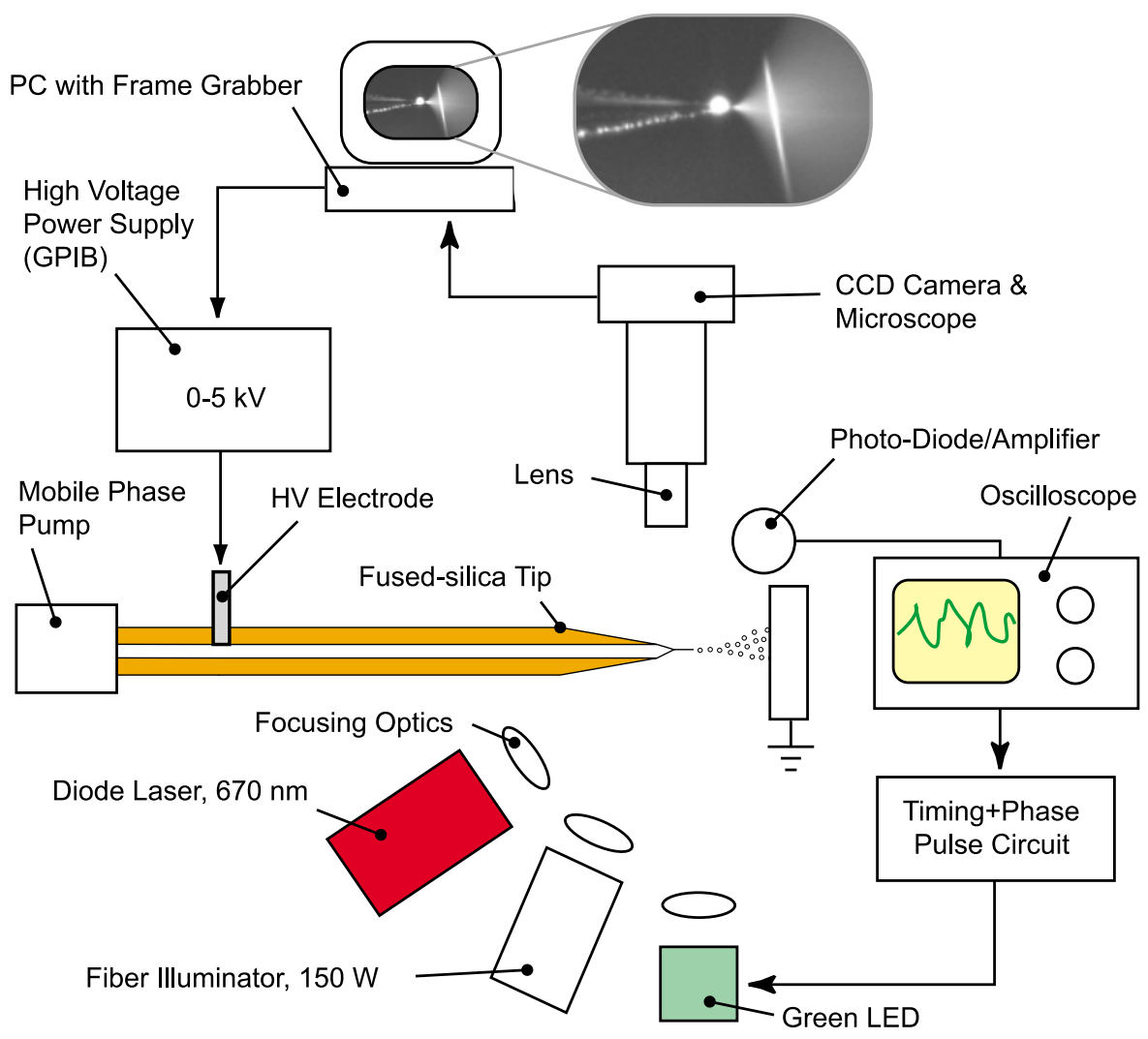

Figure 1. Schematic of the spray analysis and orthogonal control system.

either through a platinum containing proximal conductive coating applied to the emitter, or through uncoated emitters via a contact using a platinum wire microelectrode placed inside the side arm of a PEEK microtee (P-775, Upchurch Scientific, Oak Harbor, WA). High voltage $(\mathrm{HV}, 0-5 \mathrm{kV})$ was provided to the unit by a model SR350 supply (Stanford Research Systems, Sunnyvale, CA) controllable via the General Purpose Interface Bus (GPIB) interface. A fiber optic bundle connected to a $150 \mathrm{~W}$ tungsten-halogen illuminator (Model 20, Stocker and Yale, Philadelphia, PA) provided intense illumination to the area surrounding the ESI nozzle. A CCD camera (XC-ST30, Sony Electronics, Park Ridge, NJ) based video microscope was positioned orthogonal to the axis of the ESI emitter. The baffled optical tube used a $2.5 \times$ or $40 \times$ long working distance microscope objective lens that provided a total magnification of $120: 1$ or $480: 1$; total field of view was 2.5 or $0.63 \mathrm{~mm}$, respectively. The illumination angle of the fiber optic bundle was adjusted to provide maximum dark-field contrast of the electrospray plume, typically in the range of 135 to $145^{\circ}$ relative to the microscope axis.

The orthogonal spray characterization apparatus is shown schematically in Figure 1. The output of the CCD camera was fed to a personal computer (PC) equipped with both a video frame capture board and GPIB interface (National Instruments, Dallas, TX). An image analysis and high voltage control algorithm was written in the graphical LabView programming environment (National Instruments). The high voltage power supply was under the full control of the host PC via GPIB.

\section{Strobe Imaging and Scattered Light Apparatus}

Stop action images of the various periodic spray modes were documented with a modification of the above apparatus. During strobed image acquisition, the fiber optic illuminator was turned off. Illumination was provided by a bright green light emitting diode (LED) controlled by a custom built pulse and timing circuit capable of generating a $500 \mathrm{nS}$ to $1 \mu \mathrm{S}$ wide pulse. The phase of the pulse relative to an input trigger was controllable from $1 \mu \mathrm{S}$ to $500 \mathrm{mS}$. The CCD video microscope was fitted with a green bandpass filter (Melles Griot, Irvine, CA) to eliminate unwanted background and laser illumination. To provide a trigger signal for the strobe, the beam of a $25 \mathrm{~mW}, 670 \mathrm{~nm}$ diode laser was focused to a ca. $5 \mu \mathrm{m}$ diameter spot with an aspheric lens (Thorlabs, Newton, NJ), or to a $\leq 1$ $\mu \mathrm{m}$ diameter spot with a 0.85 numerical aperture microscope objective lens (Olympus America, Melville, NY). The beam was positioned to intersect the apex of the cone-jet region of the spray. The amplified output 
(a) Dripping
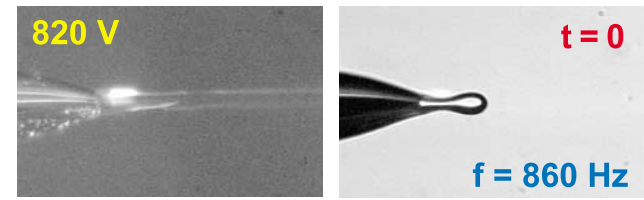

(b)

Spindle
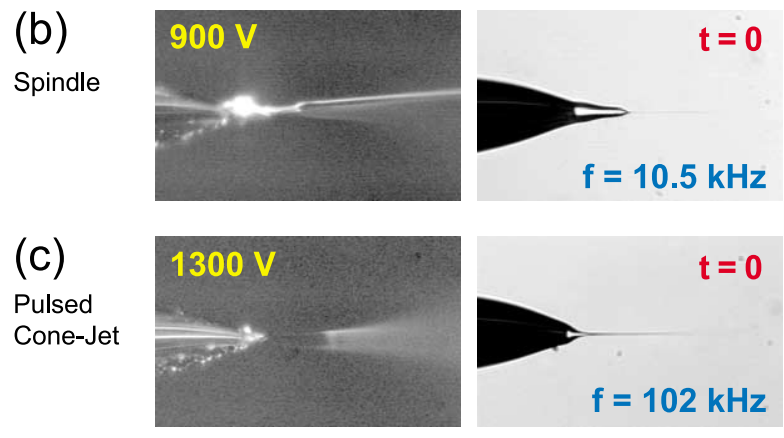

(d)

Stable

Cone-Jet
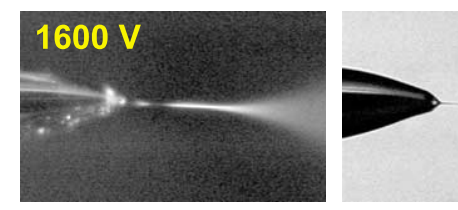

(e)

Multijet

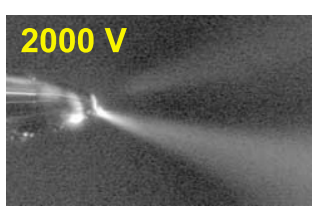

(f)

Multi-Jet/

Ram

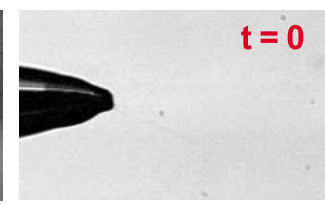

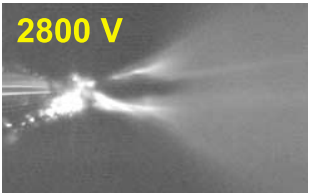
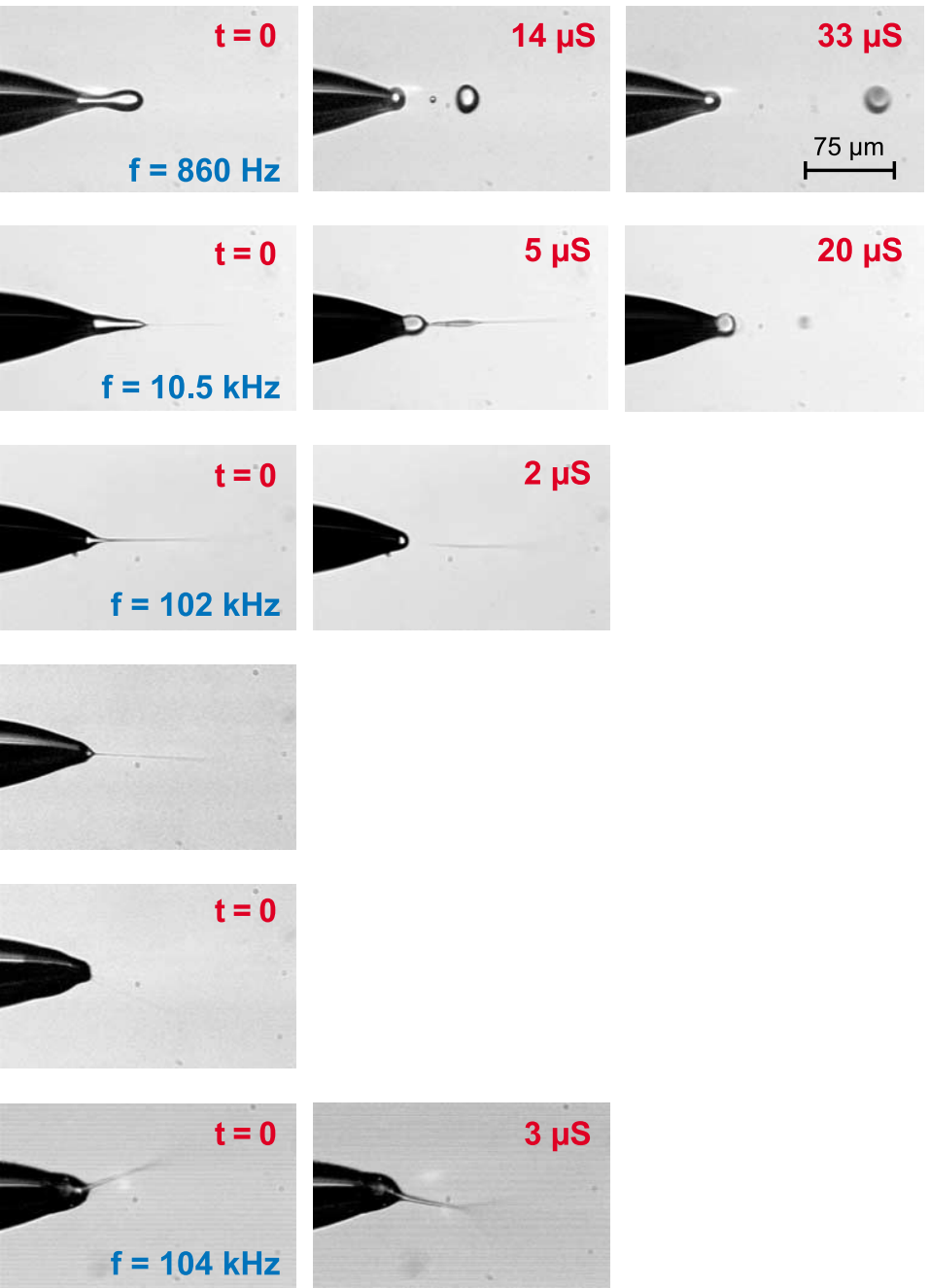

Figure 2. Scattered light (Column 1) and transmitted light (Columns 2-4) image strobe sequences (1 $\mu$ s pulse) for the commonly observed spray modes. The spray mode for each sequence is indicated on the left hand side. The applied voltage is inset in the upper left hand corner of the scattered light image for each sequence. The time delay $(\mu \mathrm{s})$ for strobed image sequences is inset in the upper right hand corner of each image. Where applicable, the periodic mode frequency of oscillation is inset in the lower right hand corner of the first strobed $(t=0)$ image. The transmitted light image in sequence $(\mathbf{d})$ was obtained with continuous illumination since no strobe trigger was possible. The emitter diameter was $15 \mu \mathrm{m}$; the mobile phase was 50\% MeOH, 1\% Acetic Acid pumped at 250 (a-e) and 580 (f) $\mathrm{nL} / \mathrm{min}$. Distance to the counter-electrode was $4 \mathrm{~mm}$. The scale bar in (a) is $75 \mu \mathrm{m}$.

from a fast $\left(10 \mathrm{MHz}\right.$ bandwidth, Gain $\left.=1 \times 10^{4} \mathrm{~V} / \mathrm{A}\right)$ photo-diode detector (Thorlabs, Newton, NJ), fitted with a $670 \mathrm{~nm}$ interference filter (Newport, Pasadena, CA), provided the LED strobe pulse trigger signal. The photodiode was positioned in a far-field diffraction plane relative to the incoming beam to maximize signal generated by scattered light from the liquid jet. The 0.85 numerical aperture objective lens was required for reliable triggering with smaller $(\approx 5 \mu \mathrm{m})$ emitters. The split output of the photodiode was also fed to a $100 \mathrm{MHz}$ digital oscilloscope (TDS3012B, Tektronix, Beaverton, OR) for frequency and waveform analysis. Any substantial change in the photodiode's output voltage, such as that caused by a moving or pulsing jet, generates a pulse trigger to illuminate the LED for $1 \mu \mathrm{S}$. The pulse width of the strobed LED was calibrated with the amplified photodiode (filter removed) and oscilloscope.

\section{Image Analysis}

Single images acquired via the frame capture board were analyzed with the Vision Builder module of LabView (National Instruments) for image correlation and spray mode analysis. Additional image analysis, correlation, and contrast enhancement was carried out with the freeware Java application ImageJ (http://rsb.info.nih.gov/ij/) on a G3 Macintosh (Apple computer, Cupertino, CA). Images used in Figures 2, 4, and 5 were optimized for contrast and brightness with black and white printing. 


\section{Mass Spectral Acquisition}

Mass spectral data was acquired on an LCQ Deca ion trap mass spectrometer (ThermoElectron Corp., San Jose, CA) fitted with a standard PV-500 nanospray source (New Objective, Inc.). Imaging of the spray plume required modification of the inlet capillary. The mass spectrometer inlet was modified with the addition of an in-house constructed capillary inlet extender. A 2 in. long by 0.020 in. i.d. stainless steel tube was fitted to the end of the conventional heated capillary inlet using a gas-tight, swage and ferrule adapter. The internal mating surfaces of the adapter were precision bored providing i.d. alignment of better than $0.001 \mathrm{in}$. Total and selected ion currents were approximately $60 \%$ of an equivalent spray without the extender in place.

Continuous infusion experiments were conducted by delivering sample from a $500 \mathrm{~nL}$ gastight syringe (Hamilton Co., Reno, NV) via the syringe pump. A Tee-based flow splitter, capable of generating two different split ratios, was placed between the pump and the nanospray source [39]. The side arm split of the Tee was fed to a two position multi-port switching valve (VICI Valco Instruments Co., Houston, TX). Each valve outlet was fitted with a $20 \mu \mathrm{m}$ i.d. restriction capillary. When the nanospray source was fitted with a $75 \mu \mathrm{m} \times 10 \mathrm{~cm}$ nanobore C18 column with a $15 \mu \mathrm{m}$ fritted tip (New Objective, Inc.), the restrictor lengths were adjusted to yield through column flow rates of 50 and $700 \mathrm{~nL} / \mathrm{min}$ with the primary pump operating at a flow rate of 2.5 $\mu \mathrm{L} / \mathrm{min}$.

The angiotensin standard was prepared in 10 and $70 \%$ acetonitrile $(0.1 \%$ formic acid) solutions at a concentration of 50 femtomole/microliter/peptide ( $50 \mathrm{nM}$ ). Full scan mass spectra were acquired continuously for each mobile phase composition while switching the splitter valve from the high- to low-flow positions every 30 s. Spectra were acquired at two different emitter (spray) potentials for each mobile phase data set. Spectra were analyzed and summed for total and selected ion currents for $(\mathrm{M}+\mathrm{H})^{1+},(\mathrm{M}+2 \mathrm{H})^{2+}$, and $(\mathrm{M}+$ $3 \mathrm{H})^{3+}$ ions for each analyte. Scattered light images of the spray plume were acquired with a CCD equipped microscope as described above.

\section{Results and Discussion}

\section{Strobed Light Illumination and Spray Mode Characterization}

The number of spray modes for a given tip geometry, mobile phase composition, and flow-rate were investigated and observed with continuous scattered (darkfield) and strobed (transmitted) light illumination. Strobed image sequences afford unambiguous determination of spray mode by providing direct characterization of pulsed spray modes. The objective of using multiple illumination techniques was to correlate image features observed in strobed illumination sequences to scattered light images. Scattered light images were chosen for the basis of automated system development because these images provide both direct viewing of the spray plume and high contrast suitable for quantitative image analysis.

Figure 2 shows a summary of the dominant spray modes observed for a typical mobile phase $(50 \%$ methanol, $1 \%$ acetic acid) at a flow rate $(250 \mathrm{~nL} / \mathrm{min})$ that is a good match for the emitter diameter $(15 \mu \mathrm{m})$. The flow rate, composition, and emitter to counter-electrode geometry were fixed in Figure sequences 2a through e. The flow rate was increased by two fold, to approx. 580 $\mu \mathrm{L} / \mathrm{min}$ in Figure sequence $2 \mathrm{f}$. The applied voltage was initialized at 800 volts (2a) and increased in $20-50 \mathrm{~V}$ increments until a change in spray mode was observed. Differences in pulsation frequency or spray mode were observed with voltage changes as small as $1 \%(\approx 25 \mathrm{~V})$.

With established spray mode definitions [22, 29], a typical $15 \mu \mathrm{m}$ i.d. emitter yields the following spray modes when operated within an "optimal" (200-300 $\mathrm{nL} / \mathrm{min}$ ) range and a mobile phase of $50 \%$ methanol: dripping, micro-dripping, spindle, oscillatory (pulsed) cone-jet, stable cone-jet, and multi-jet. Operation of the same emitter at a higher $(500-600 \mathrm{~nL} / \mathrm{min})$ flow rate added new spray modes (multi-spindle and ramified jet) and eliminated others (stable cone-jet). Many of the spray modes were oscillatory and exhibited highly periodic behavior over a wide range of frequencies $(0.1$ $\mathrm{Hz}$ to $100 \mathrm{kHz}$ ) A trigger pulse for strobed illumination for the stable cone-jet spray mode could not be generated; continuous LED illumination was substituted in Figure 2d. No significant differences were observed between strobed illumination (with a freely running external trigger) and continuous illumination images for the stable cone-jet.

At low applied voltage, the dripping and microdripping spray modes were the dominant spray modes. Droplets were relatively large, with an initial diameter that is close to, or larger than, the diameter of the emitter. In the Figure 2a sequence, leading and tailing droplets have an approximate diameter of 20 and $5 \mu \mathrm{m}$ respectively. As the applied voltage was increased, droplet diameter decreased as frequency increased. In these two spray modes, no aerosol plume is observed. Furthermore, mass transfer of mobile phase off the emitter is often incomplete; a significant portion of liquid can remain in contact with the tapered portion of the emitter.

Observed spray modes with a distinct aerosol plume included the spindle, pulsed cone-jet, cone-jet, multi-jet, and multi-jet/ramified-jet. The spindle and pulsed cone-jet spray modes are notable and yield Taylor cone-jet formation with a fractional duty cycle; Figure $2 \mathrm{~b}$ and $\mathrm{c}$ provide direct observation of this behavior. Instability between surface tension, which drives to minimize surface area, and electrostatic repulsion, creates this oscillatory behavior [34]. When the voltage was increased by approximately $100 \mathrm{~V}$ beyond the microdripping range, the spindle spray mode resulted. This 
(a)
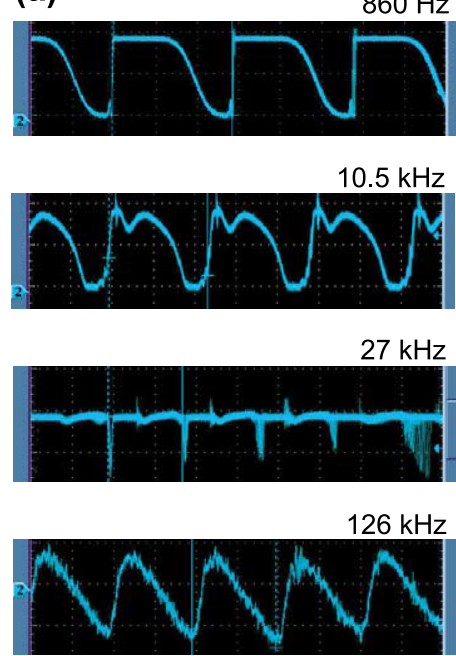

(b)

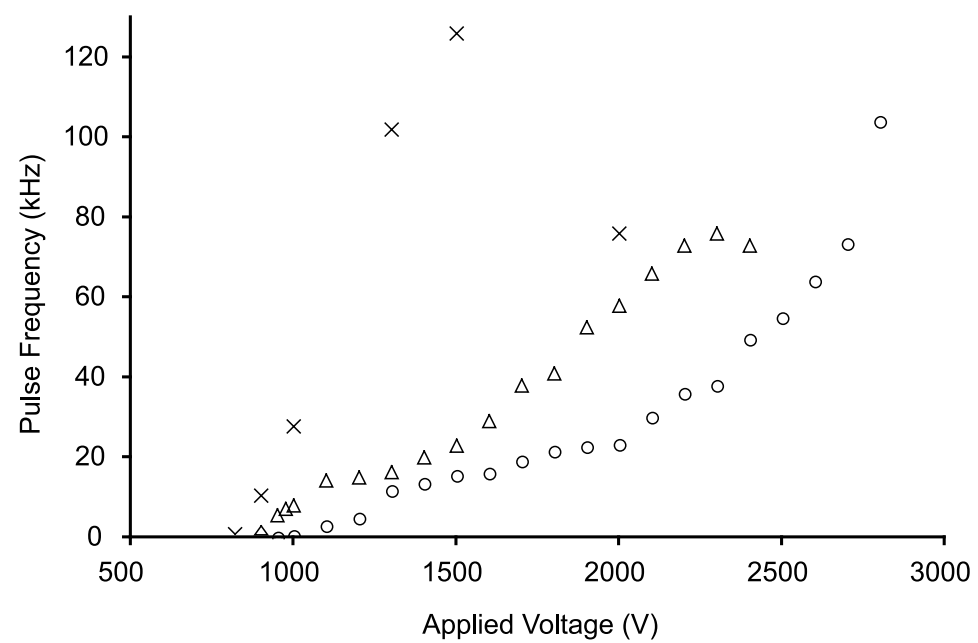

Figure 3. Oscilloscope waveforms (a) and frequency versus voltage data (b) for two different emitters. $X=15 \mu \mathrm{m}$ tip @ $250 \mathrm{~nL} / \mathrm{min}$, open circle $=15 \mu \mathrm{m}$ tip @ $580 \mathrm{~nL} / \mathrm{min}$, open triangle $=8 \mu \mathrm{m}$ tip @ $400 \mathrm{~nL} / \mathrm{min}$. The oscilloscope waveforms were recorded for the $15 \mu \mathrm{m}$ tip operated at 250 $\mathrm{nL} / \mathrm{min}$. Mobile phase composition was 50\% methanol, $1 \%$ acetic acid. Distance to the counter electrode was $4 \mathrm{~mm}$.

spray mode was characterized by the generation of large $(1-5 \mu \mathrm{m})$ droplets in addition to the cone-jet plume. These larger droplets pinch off the end of the elongated cone when it collapses (Figure $2 b$ ). The duty cycle of the cone-jet formation with this spray mode has been observed to be as low as $10 \%$, with duty cycle and oscillation frequency increasing as applied voltage is raised. A further increase in voltage eliminated the formation of the larger droplets altogether and resulted in the pulsed cone-jet spray mode. This spray mode (Figure 2c) was characterized by transient cone-jet formation over a wide frequency range (20 to $100 \mathrm{kHz}$ ). A continued increase in voltage resulted in a stable conejet (Figure 2d). Tuning for a stable cone-jet spray mode was only possible when flow rate was between 100 to $300 \mathrm{~nL} / \mathrm{min}$. A further increase in voltage resulted in the multi-jet spray mode (Figure 2e) in which multiple cone-jets formed on the emitter. Such multiple jets can form simultaneously (Figure 2e) or alternately pulsing from jet-to-jet (Figure 2f). The oscillation frequency for the multi-jet spray mode was observed to be in excess of $100 \mathrm{kHz}$. An increase in the flow rate to ca. $500 \mathrm{~nL} / \mathrm{min}$ resulted in the multi-spindle spray mode which prevented the formation of the stable cone-jet over the entire range of applied voltage. At higher flow rates a further increase in voltage resulted in the transformation from the multi-spindle to the ramified-jet spray mode in which daughter cone-jets form in a fractal fashion along a central liquid jet [22].

The fundamental frequency of oscillation (in the lower right hand corner of each image) was independently measured with the laser/photodiode/oscilloscope combination. Figure 3a shows example oscilloscope traces for selected oscillatory spray modes observed in Figure 2. Frequencies ranging from $860 \mathrm{~Hz}$ for the dripping spray mode, to $102 \mathrm{kHz}$ for the pulsed cone-jet spray mode, were observed. The hundred kilohertz frequency range is significantly higher range than low kilohertz frequencies reported elsewhere [34, 35]. This result may in part be due to differences in emitter geometry and flow rate. Increasing the flow rate from 250 to $580 \mathrm{~nL} / \mathrm{min}$ (Figure $3 \mathrm{~b}$ ) has a profound effect on pulsation frequency. The oscillation frequency for the pulsed cone-jet spray mode, for example, drops from approximately $100 \mathrm{kHz}$ at $250 \mathrm{~nL} / \mathrm{min}$ to a $20-50$ $\mathrm{kHz}$ range at $580 \mathrm{~nL} / \mathrm{min}$. In addition, substituting an 8 $\mu \mathrm{m}$ tip (at an intermediate flow rate of $\approx 400 \mathrm{~nL} / \mathrm{min}$ ) resulted in a $60-80 \mathrm{kHz}$ pulsed cone-jet with a the spindle spray mode frequency of $\approx 30 \mathrm{kHz}$. Frequency components in excess of $300 \mathrm{kHz}$ have been observed with a $5 \mu \mathrm{m}$ diameter emitter for flow rates between 50-100 nL/min. Smaller tips and lower flow rates tend toward higher pulsation frequencies for both the spindle and pulsed cone-jet spray modes. Higher natural pulsation frequencies would appear to be desirable for ESI-MS [35] since spray modulation is pushed well above the millisecond time scale.

\section{Correlation of Spray Mode in Scattered Light Images}

As shown in Figure 2, there are distinct features of each spray mode in the scattered light image that can be explained by corresponding strobe images. For example, a high contrast, white line (defined as a "stream line") is observed (Figure $2 \mathrm{~b}$ and Figure 4) against a weaker plume background. When a strobe image is digitally superimposed over the scattered light image (not shown), the white line of the reflected light image corresponds to the edges of the larger droplets pinching 

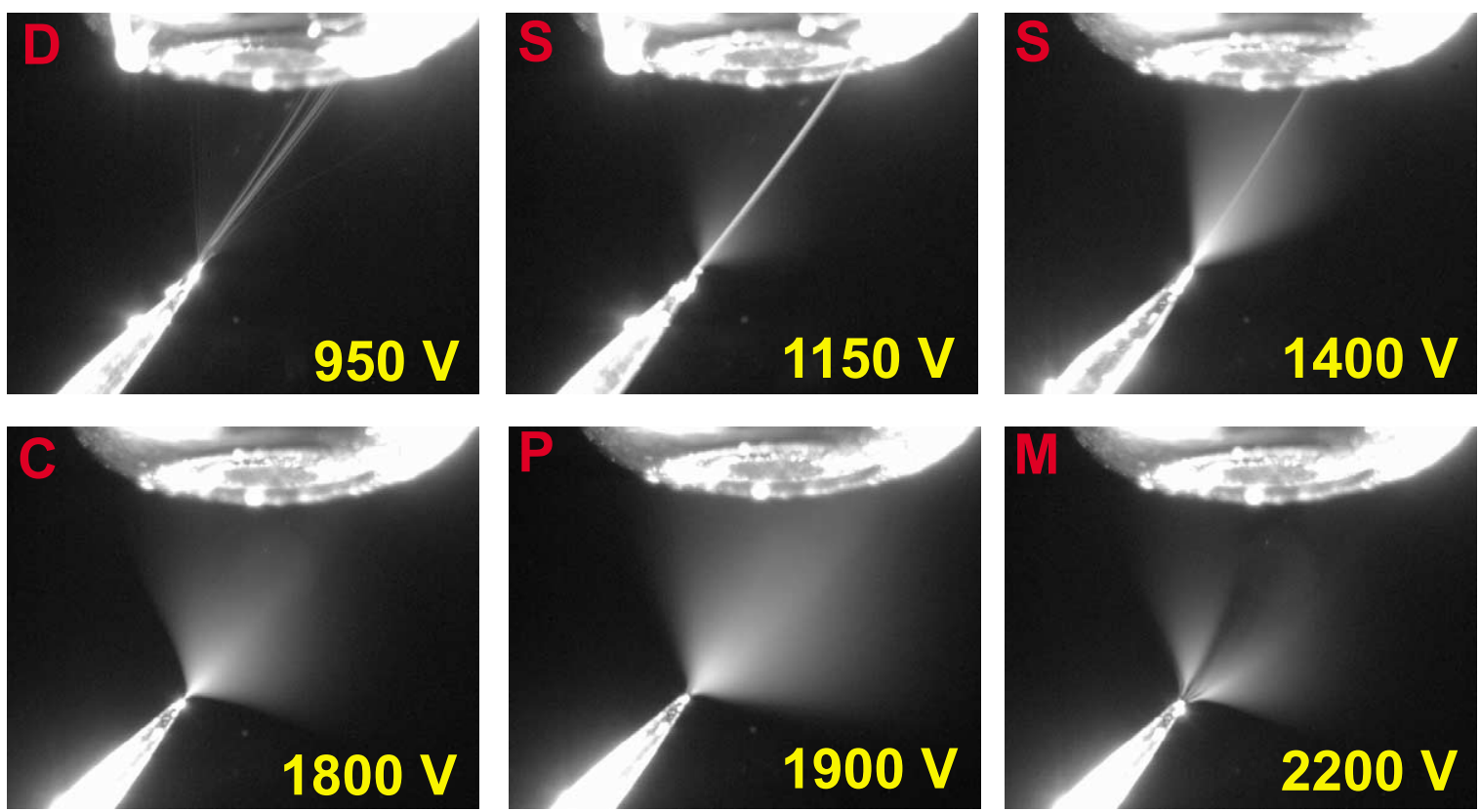

Figure 4. Spray modes observed at low magnification with scattered light on a conventional nanospray equipped ion trap mass spectrometer. The tip size is $15 \mu \mathrm{m}$. The mobile phase is $30 \% \mathrm{ACN}$, $0.1 \%$ formic acid flowing at $300 \mathrm{~nL} / \mathrm{min}$. The applied voltage is indicated in the lower right hand corner of each frame. The spray mode $(\mathrm{C}=$ cone-jet, $\mathrm{D}=$ dripping, $\mathrm{M}=$ multi-jet, $\mathrm{P}=$ pulsed cone-jet, $\mathrm{S}=$ spindle) is indicated by the (red) letter in the upper left hand corner of each frame.

off the end of the elongated cone. Because droplets are produced at greater than $10 \mathrm{kHz}$, the video camera captures only a blurred line or lines that correspond to the edges of the larger droplets. Table 1 summarizes the salient features observed in scattered light images for the commonly observed spray modes. Figure 4 shows scattered light spray images at a lower magnification and demonstrates the persistence of the larger droplets through the plume. These droplets were observed to impact and collect on the side of the inlet capillary counter electrode. Spray mode identification and classification was performed by correlation of the high magnification reflected light and strobe sequences (Figure 2) with the low magnification scattered light spray images (Figure 4). These reflected light image observa- tions (Table 1) form the basis of an automated image analysis and voltage control algorithm.

Observations made with strobed LED illumination, in combination with standard $(30 \mathrm{~Hz})$ video acquisition, has limitations. LED illumination was insufficient to capture the weak refraction of (sub)micrometer plume droplets, although the critical cone/jet region was readily observed. This system can only observe periodic features of spray morphology; non-repetitive events are lost. Strobed images captured here can only record those image features that repeat on each trigger provided by the photodiode. The time required to acquire a single image frame, composed of two fields with a 2:1 interlace is ca. $0.03 \mathrm{~s}$. Each horizontal line of the image requires $63.5 \mu \mathrm{s}$ [40]. This relatively slow image acquisition typically

Table 1. Image features of commonly observed spray modes ${ }^{\mathrm{a}}$

\begin{tabular}{llll}
\hline Spray mode & Jet region observed & Plume observed & Stream lines observed \\
\hline \hline Dripping/Microdripping & No & No & Yes, possibly multiple \\
Spindle & Yes & Yes & Yes, single \\
Pulsed Cone-jet & Yes, w/possible & Yes & No \\
& width increase & & No \\
Stable Cone-jet & Yes & Yes & No \\
Multi-jet & Yes, multiple & Yes, multiple & Yes, always multiple \\
Multi-spindle & Yes, multiple & Yes, multiple & No \\
(Multi) Ramified jet ${ }^{\text {c }}$ & Yes, multiple, & Yes, multiple & \\
& Length Extended & & \\
\hline
\end{tabular}

aSummary of multiple spray mode observations made with emitter diameters that range from 5 to $30 \mu \mathrm{m}$ in diameter, flow rates of $50 \mathrm{~nL} / \mathrm{min}$ to 2 $\mu \mathrm{L} / \mathrm{min}$, applied voltage of 500 to $5,000 \mathrm{~V}$, and mobile phase composition of $2 \%$ to $98 \%$ organic co-solvent.

observable only with low $(\leq 50 \%)$ organic co-solvent at overdriven flow rates.

'Observable when heavily overdriving flow rate for a given emitter diameter (e.g. operating a $15 \mu \mathrm{m}$ emitter at 1-2 $\mu \mathrm{L} / \mathrm{min}$ ). 

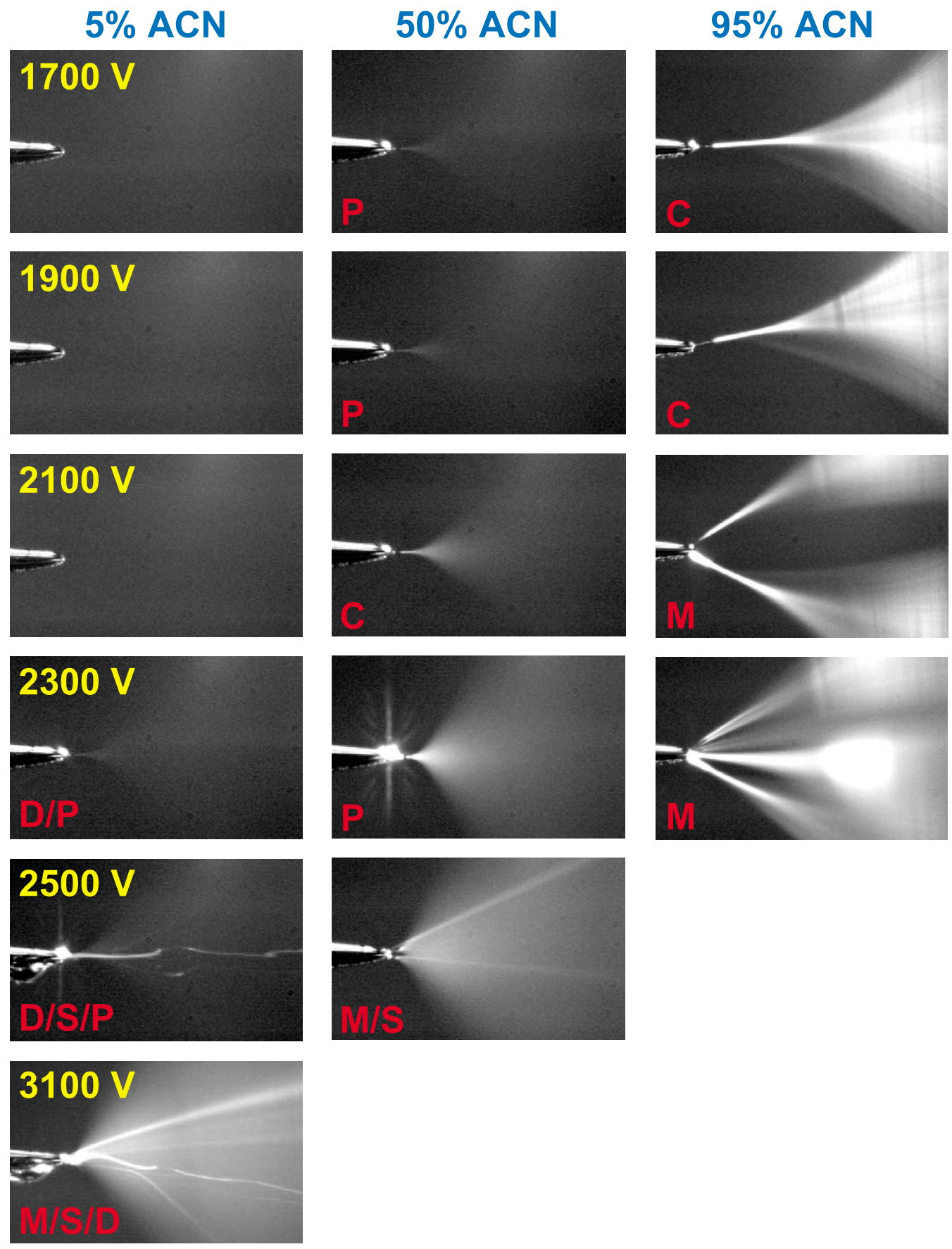

Figure 5. Effect of mobile phase composition on spray mode for a fixed flow rate. Percentage of ACN $(0.1 \%$ formic acid $)$ is indicated above each column. Applied voltage is indicated on the left hand side. The spray mode is labeled in the lower left hand corner of each frame $(\mathrm{C}=$ cone-jet, $\mathrm{D}=$ dripping, $\mathrm{M}=$ multi-jet, $\mathrm{P}=$ pulsed cone-jet, $\mathrm{S}=$ spindle). Multiple letters indicate mixed modes. The emitter diameter was $30 \mu \mathrm{m}$; the flow rate was approximately $500 \mathrm{~nL} / \mathrm{min}$. The counter-electrode distance was $4.5 \mathrm{~mm}$.

results in multiple LED flashes that illuminate each image frame. In effect, each image frame is a multiple exposure. Image features not present upon successive LED flashes will have insufficient contrast to be recorded. Because periodic image features yield persistent contrast on each LED flash, the images are readily recorded at the standard video rate, and in fact, are even suitable for direct viewing with the human eye.

\section{Effect of Mobile Phase Composition}

The effect of a reverse phase LC experiment on electrospray morphology and spray mode is considerable given the wide variation in surface tension and viscosity [41] for the typical 5 to $95 \%$ ACN gradient. Figure 5 illustrates the dramatic effect mobile phase composition has on electrospray onset voltage and spray mode. The 


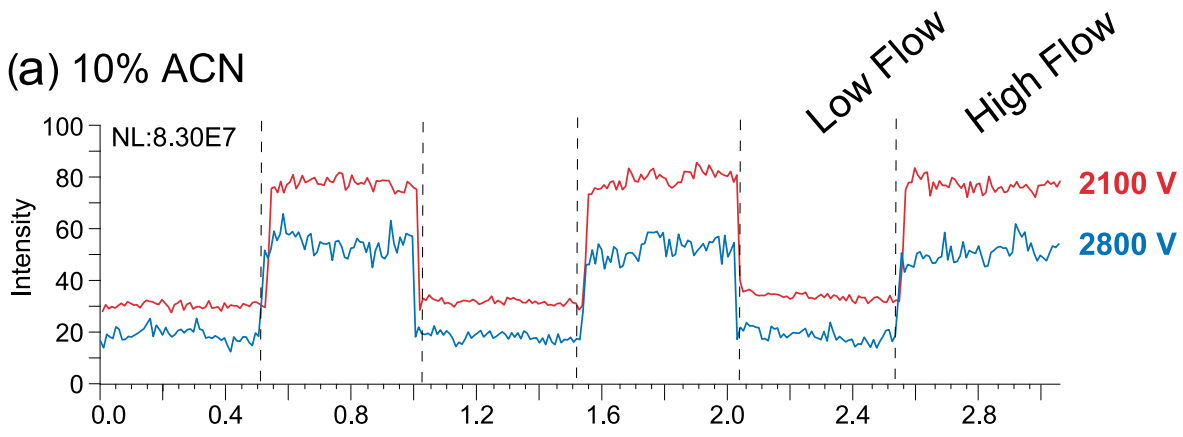

(b) $70 \%$ ACN

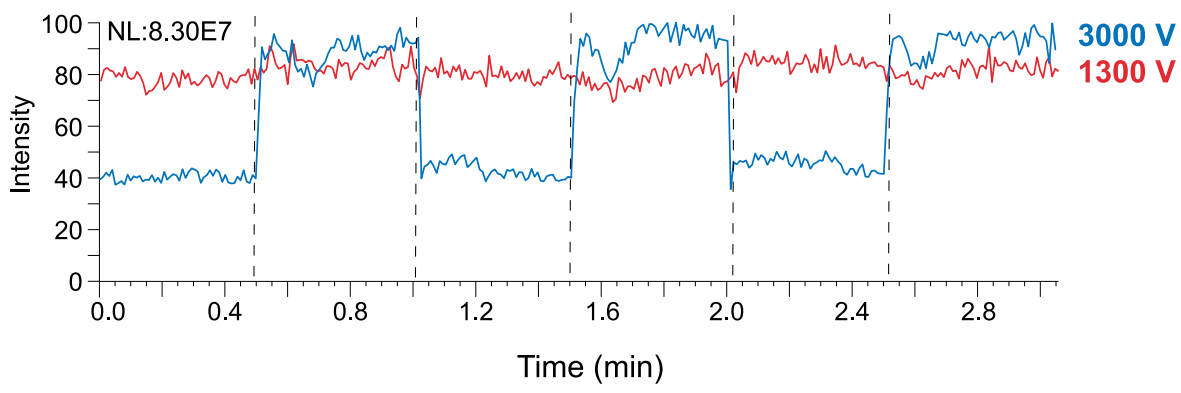

Figure 6. Summed selected ion current (SIC) for fifteen $(M+H)^{+1},(M+2 H)^{+2}$, and $(M+3 H)^{+3}$ molecular ions for a mixture of five angiotensin variants at a concentration of $50 \mathrm{nM} /$ peptide. The mixture was sprayed through a 75 um i.d. column $/ 15 \mu \mathrm{m}$ i.d. fritted emitter by continuous infusion. Mobile phase was delivered by a syringe pump and switchable flow splitter to deliver a through column flow ratae of 50 or $700 \mathrm{~nL} / \mathrm{min}$. The flow was switched from 50 to $700 \mathrm{~nL} / \mathrm{min}$ approximately every $30 \mathrm{~s}$. For each composition, the experiment was repeated at two different emitter voltages. (a) Total SIC; mobile phase composition of $10 \% \mathrm{ACN}$ ( $0.1 \%$ formic acid); emitter voltages of $2100 \mathrm{~V}$ (red) and $2800 \mathrm{~V}$ (blue). (b) Total SIC; mobile phase composition of $70 \% \mathrm{ACN}(0.1 \%$ formic acid); emitter voltages of $1300 \mathrm{~V}$ (red) and $3000 \mathrm{~V}$ (blue). Results for (a) and (b) are plotted identically with 100\% intensity equal to $8.3 \mathrm{E} 7$ counts. The emitter position was fixed for all experiments.

applied voltage was varied and the spray mode was characterized for three different mobile phase compositions $(5,50$, and $95 \%$ acetonitrile, $0.1 \%$ formic acid, respectively) at a calibrated flow rate. The threshold voltage for plume formation drops from the relatively high value of $2300 \mathrm{~V}$ at $5 \% \mathrm{ACN}$ to 1700 and $1400 \mathrm{~V}$ (not shown) for 50 and $95 \% \mathrm{ACN}$, respectively. A voltage observed to generate a stable cone-jet spray mode at $50 \% \mathrm{ACN}(2100 \mathrm{~V})$ generated no plume for $5 \% \mathrm{ACN}$ and a chaotic multi-jet spray mode at $95 \% \mathrm{ACN}$. A fixed applied voltage is insufficient to maintain the most desirable spray mode or modes (spindle, pulsed conejet, cone-jet) throughout the gradient. The typical approach used in this situation is to tune for an optimal spray at a composition of greatest chromatographic relevance (e.g., $20-30 \% \mathrm{ACN}$ for peptide analysis) or to use some form of pneumatic assistance to normalize droplet generation. Either approach represents a compromise from optimal ESI conditions. An alternative solution is to vary a controllable parameter such as voltage, emitter to counter-electrode distance, or flow rate, so as to maintain a desirable spray mode or modes throughout the run.

\section{Observation of Mass Spectral Data Quality and Spray Mode}

The results of an initial study to observe potential impact of spray mode on ion current and MS data quality are shown in Figures 6, 7, and 8. Preliminary observations demonstrated that spray mode effects are difficult to observe at high analyte $(\mu \mathrm{M})$ concentration for peptides and suggested the exploration of effects at both low flow rate and low concentration. The peptide standard mixtures were prepared at a concentration (50 $\mathrm{nM}$ ) above, but near to, the concentration limit of detection for spraying by continuous infusion.

The summed, selected ion signals for the flow rate switching experiment are shown in Figure 6. The selected ion current for the fifteen relevant $[\mathrm{M}+\mathrm{H}]^{1+}$, $[\mathrm{M}$ $+2 \mathrm{H}]^{2+}$, and $[\mathrm{M}+3 \mathrm{H}]^{3+}$ molecular ions (see Figure 6 caption) were summed from the full scan mass spectra. A mobile phase composition of $10 \%$ ACN with a flow rate of $50 \mathrm{~nL} / \mathrm{min}$ yielded approximately 56 and $67 \%$ of the signal obtained at $700 \mathrm{~nL} / \mathrm{min}$ for applied voltages of 2800 and $2100 \mathrm{~V}$, respectively. A mobile phase composition of $70 \%$ ACN with a flow rate of $50 \mathrm{~nL} / \mathrm{min}$ 
(a) $10 \% \mathrm{ACN}, 50 \mathrm{~nL} / \mathrm{min}$

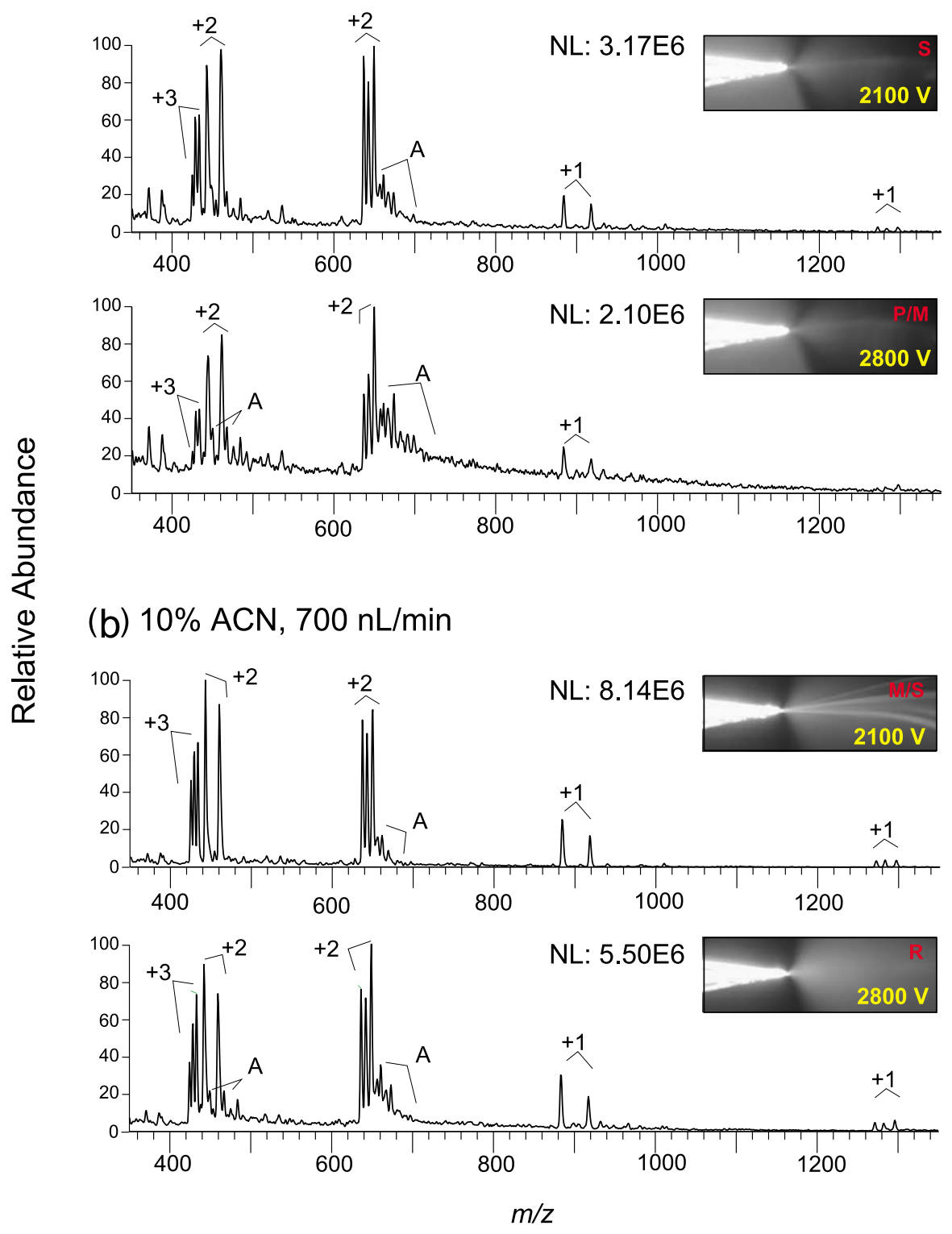

Figure 7. Representative full scan mass spectra of the angiotensin mixture $(10 \% \mathrm{ACN})$ used to generate the SIC data presented in Figure 6a. Each mass spectrum shown is the sum of 10 individual scans recorded for each flow rate and emitter voltage. The spray plume image for each spectrum is shown in the inset. (a) Flow rate of $50 \mathrm{~nL} / \mathrm{min}$ with emitter voltages of 2100 and $2800 \mathrm{~V}$. (b) Flow rate of $700 \mathrm{~nL} / \mathrm{min}$ with emitter voltages of 2100 and $2800 \mathrm{~V}$. The letter in the upper right hand corner of the spray image indicates the spray mode observed $(\mathrm{S}=$ spindle, $\mathrm{P} / \mathrm{M}=$ pulsed multi-jet, $\mathrm{M} / \mathrm{S}=$ multi-spindle, $\mathrm{R}=$ ramified jet). The $(\mathrm{M}+\mathrm{H})^{+1},(\mathrm{M}+2 \mathrm{H})^{+2}$, and $(\mathrm{M}+3 \mathrm{H})^{+3}$ molecular ions are denoted with $+1,+2,+3$, respectively; A denotes adducts. The base peak ion intensity for each spectrum is shown to the left of each plume image.

yielded approximately 46 and $97 \%$ of the signal obtained at $700 \mathrm{~nL} / \mathrm{min}$ for applied voltages of 3000 and $1300 \mathrm{~V}$, respectively. The change in molecular ion intensity at high and low flow rates correspond to different spray modes observed at high and low voltages. Although simple summation does not take detector efficiency differences for multiply charged ions into account, the data strongly suggests the source exhibits mass flow sensitivity when the flow rate is dropped to $50 \mathrm{~nL} / \mathrm{min}$. This apparent mass flow sensitivity at 50
$\mathrm{nL} / \mathrm{min}$ is minimized, or in the case of $70 \% \mathrm{ACN}$ is virtually eliminated, at the lower applied spray potentials when the stable cone-jet mode is observed.

Figures 7 and 8 show representative full scan mass spectra for each mobile phase composition and flow rate along with the recorded spray plume image. Considerable differences in ion current, $\mathrm{S} / \mathrm{N}$, adduct formation, and charge state distribution were observed. The highest quality spectra (Figure 7) with the best S/N were recorded at $2100 \mathrm{~V}$ for both 50 and $700 \mathrm{~nL} / \mathrm{min}$ 
(a) $70 \% \mathrm{ACN}, 50 \mathrm{~nL} / \mathrm{min}$

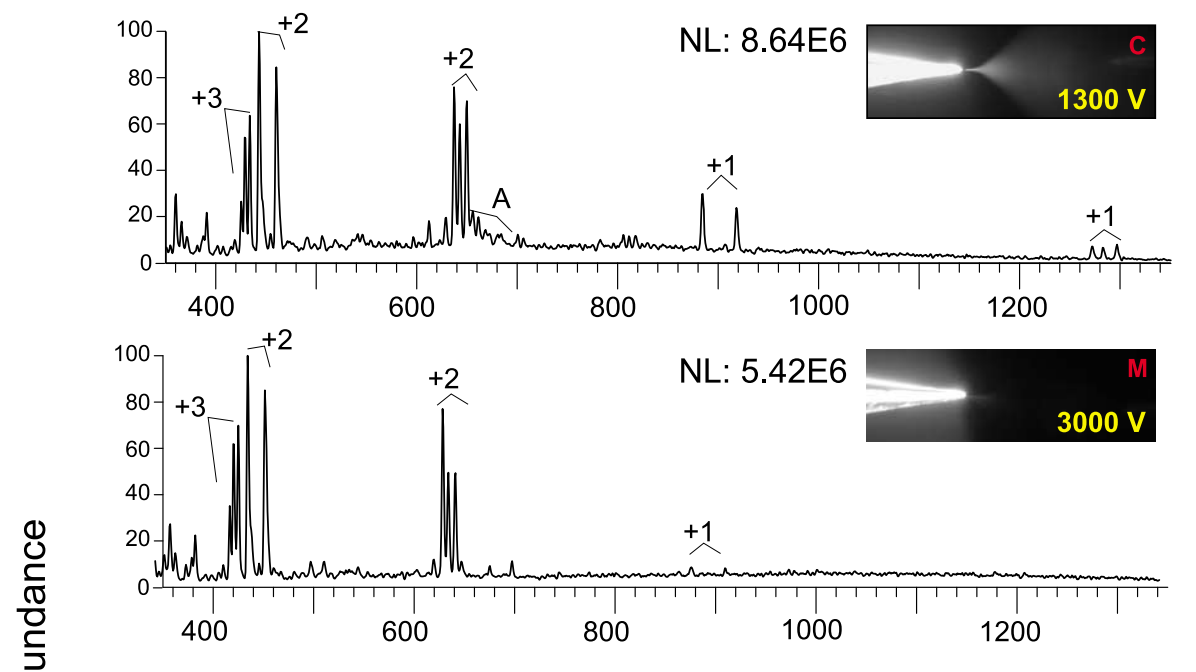

(b) $70 \% \mathrm{ACN}, 700 \mathrm{~nL} / \mathrm{min}$
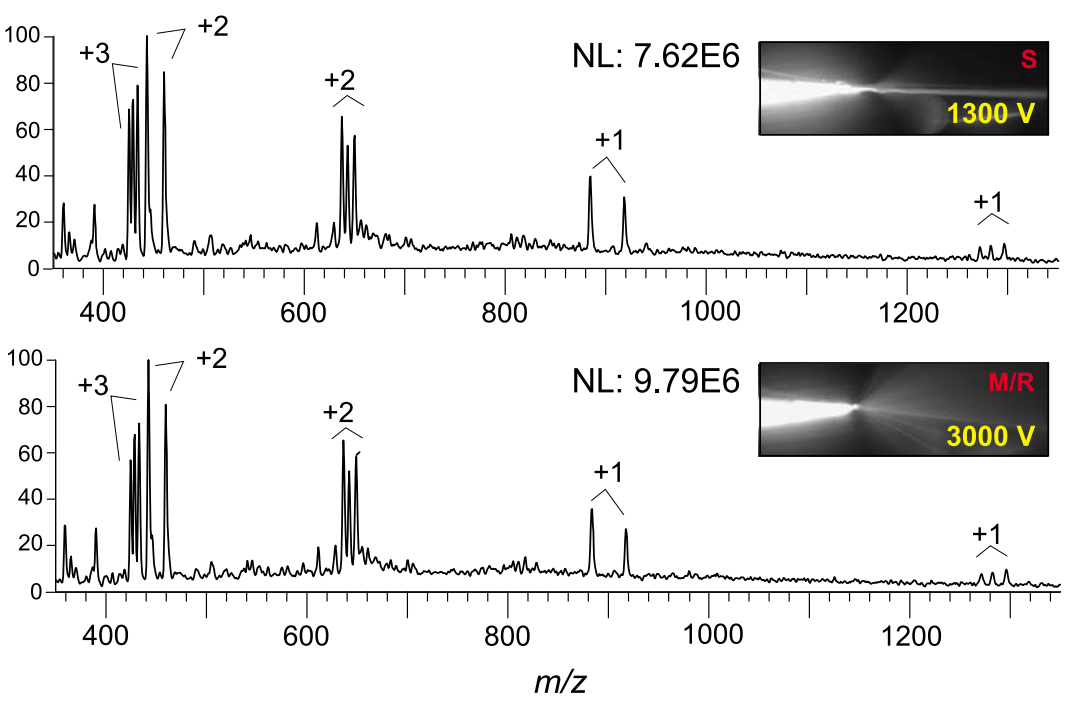

Figure 8. Representative full scan mass spectra of the angiotensin mixture (70\% ACN) used to generate the SIC data presented in Figure 6b. Each mass spectrum shown is the sum of 10 individual scans recorded for each flow rate and emitter voltage. The spray plume image for each spectrum is shown in the inset. (a) Flow rate of $50 \mathrm{~nL} / \mathrm{min}$ with emitter voltages of 1300 and $3000 \mathrm{~V}$. (b) Flow rate of $700 \mathrm{~nL} / \mathrm{min}$ with emitter voltages of $1300 \mathrm{~V}$ and $3000 \mathrm{~V}$. The letter in the upper right hand corner of the spray image indicates the spray mode observed $(C=$ scone-jet, $M=$ multi-jet, $S=$ spindle, $M / R$ $=$ multi-ramified jet). The $(\mathrm{M}+\mathrm{H})^{+1},(\mathrm{M}+2 \mathrm{H})^{+2}$, and $(\mathrm{M}+3 \mathrm{H})^{+3}$ molecular ions are denoted with $+1,+2,+3$, respectively; A denotes adducts. The base peak ion intensity for each spectrum is shown to the left of each plume image.

and corresponded to the spindle and multi-spindle modes respectively, at $10 \%$ ACN. At $70 \% \mathrm{ACN}$, higher quality spectra (Figure 8) were recorded at $1300 \mathrm{~V}$ at 50 and $700 \mathrm{~nL} / \mathrm{min}$, corresponding to the cone-jet and spindle modes respectively. The poorest quality mass spectra with both reduced $\mathrm{S} / \mathrm{N}$ and greater adduct formation were observed for the pulsed multi-jet and multi-jet spray modes. The $[\mathrm{M}+\mathrm{H}]^{1+}$ molecular ions were not observed with spectra acquired in multi-jet modes at the low flow rate. The highest quality spectra were observed with the spindle, multi-spindle, and stable cone-jet modes. The cone-jet mode also corresponded to the only case where mass flow sensitivity was not a significant factor at low flow rates.

\section{Automated Orthogonal Control}

The orthogonal illumination and imaging system (Figure 1) generates signal for a feedback loop comprised of a analysis and control algorithm that adjusts applied 


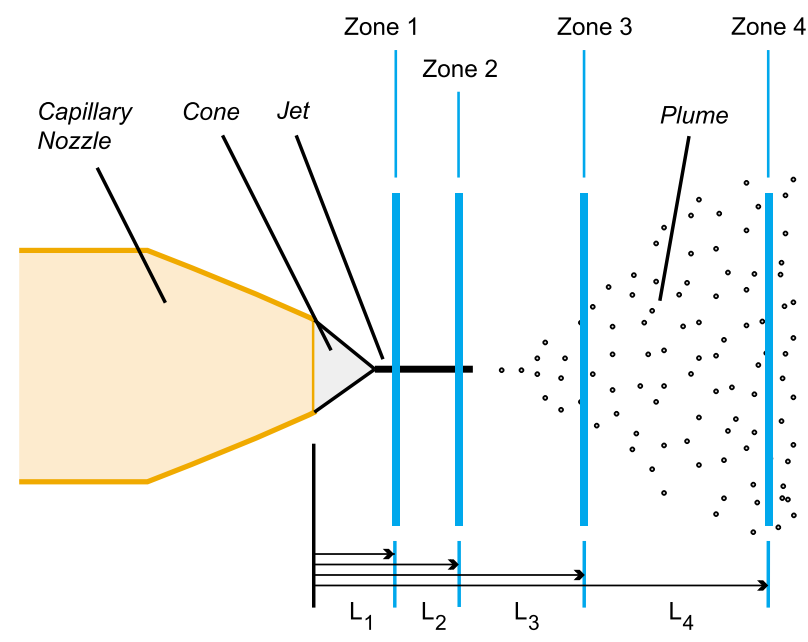

Figure 9. Geometry of the four region-of-interest (ROI) zones used by the image analysis algorithm. The values of $\mathrm{L}_{1}$ through $\mathrm{L}_{4}$ were 95, 195, 780, and $1655 \mu \mathrm{m}$ respectively, for the $30 \mu \mathrm{m}$ diameter emitter used in the example.

voltage so that a particular spray mode is obtained and maintained. The analysis is based on empirical image characterization and feature measurement for spray mode determination. The strategy for automated feedback and control is to make quantitative image measurements following the observations summarized in Table 1 for a priori determination of spray mode.

Spray mode determination is based on image morphology using edge detection and location within predefined areas surrounding the emitter and are referred to as regions-of-interest (ROI). Four linear (one-dimensional) ROI zones are established with strategic positions located perpendicular to the emitter tip (Figure 9). Zone one is positioned to probe the area corresponding to the cone-jet transition. Zone two, positioned farther away from the emitter but close to zone one, probes the middle of the jet region. Zones one and two provide information about the presence of liquid discharge from the tip and establish the number of jets or streams emitted. Zone three is positioned along leading edge of the aerosol plume and distinguish large droplet emis- sion and plume formation. Zone four is placed twothirds along the length the observable plume and confirms the presence of large droplet emission through detection of stream lines. Because the shape of the plume will be influenced by flow rate and emitter/ source geometry, the optimal choice of ROI location will vary. For this study, the distance from the emitter tip $\left(\mathrm{L}_{1}-\mathrm{L}_{4}\right)$ was $95,290,875$, and $1750 \mu \mathrm{m}$ for zones one through four, respectively. A one-dimensional edge detection scheme, similar to a first-order derivative operator [42], is based on the pixel intensity difference between background and foreground combined with the slope of the transition. This scheme determines the location and number of edges within each zone. Table 2 summarizes the number of edges and distance criteria found in each ROI zone for the common spray modes. A control algorithm that uses a conditional logic scheme based on edge number and edge criteria is used to adjust applied voltage to maintain desirable spray modes. In this scheme, the detection of dripping or spindle spray modes cause the applied voltage to be raised, while multi-jet or multi-spindle spray modes cause the voltage to be lowered. If a stable cone-jet, or pulsed cone jet is detected, then the voltage is left unchanged. The voltage is typically changed in $50 \mathrm{~V}$ increments, which typically provides stable transitions between spray modes. The cone-jet and pulsed cone-jet spray modes are thus approached from either under- or over-voltage conditions over a discrete number of image acquisition and analysis cycles., As many as 50 cycles may be required to reach sufficient voltage for a cone-jet spray mode with initial spray modes that are far from optimal, such as the dripping spray mode. As few as two to three cycles are sufficient to generate a cone-jet spray mode for spray modes close to optimal, such as the spindle spray mode. The conditional logic is easily modified so as to maintain other modes, such as controlling the number of jets in the multi-jet spray mode. Furthermore, the system incorporates an automated start-up procedure in which the emitter is brought from a non-spraying to spraying condition. This automated start-up is accomplished by incremen-

Table 2. Region of interest (ROI) image features of the common spray modes ${ }^{\mathrm{a}}$

\begin{tabular}{|c|c|c|c|c|c|c|}
\hline \multirow[b]{2}{*}{ Spray mode } & \multirow[b]{2}{*}{ Zone 1 no. edges } & \multirow[b]{2}{*}{ Zone 2 no. edges } & \multicolumn{2}{|c|}{ Zone 3} & \multicolumn{2}{|c|}{ Zone 4} \\
\hline & & & $\begin{array}{c}\text { no. } \\
\text { edges }\end{array}$ & distance $^{b}$ & $\begin{array}{c}\text { no. } \\
\text { edges }\end{array}$ & distance \\
\hline Dripping/micro-dripping & 2 (or 4) & 2 (or 4 ) & 2 (or 4) & Typ. $\geq X^{c}$ & 2 (or 4) & $\geq X$ \\
\hline Spindle & 2 & 2 & 2 & $<\mathrm{X}$ & 2 & $<\mathrm{X}$ \\
\hline Pulsed cone-jet & $\geq 2$ & 2 & 2 & $>>X$ & $I_{N D}^{d}$ & IND \\
\hline Stable cone-jet & 2 & 2 & 2 & $>>X$ & IND & IND \\
\hline Multi-jet & $\geq 2$ & $>2$ & $>2$ & $>X$ & IND & IND \\
\hline Multi-spindle & 2 or 4 & 2 or 4 & 4 & $<\mathrm{X}$ & 4 & $<\mathrm{X}$ \\
\hline
\end{tabular}

aZone analysis of the zones established in Figure 9 for spray modes encountered with an optimal or nearly optimal flow rate for a given emitter diameter. This table does not take into account an overdriven tip and does not include all possible spray modes or mixed spray modes.

${ }^{\mathrm{b}}$ Distance between dark-to-light and light-to-dark edge pairs.

${ }^{c} X$ is a criterion distance which is typically on the order ot 3-5 times the value of the tip diameter.

dIND = indeterminate 
tally increasing the applied voltage from a start value until liquid emission is detected in zones one and two. After the detection event, control switches to the algorithm described above.

To test performance of the system with changes in mobile phase flow rate, a $30 \mu \mathrm{m}$ i.d. tip was connected to the syringe pump delivering mobile phase (aqueous solution of $50 \%$ methanol, $2 \%$ acetic acid) at a flow rate between $100 \mathrm{~nL} / \mathrm{min}$ to $2 \mu \mathrm{L} / \mathrm{min}$. After starting liquid flow at an initial rate of $250 \mathrm{~nL} / \mathrm{min}$, the computer system was initialized to automatically establish liquid emission. The applied voltage was initially set to $1000 \mathrm{~V}$ and the first image was acquired. If no edges were detected in zones one and two, the voltage was automatically increased by $200 \mathrm{~V}$ and another image was acquired. This process was repeated until two edges were established in zones one and two. After the start-up phase, the algorithm switched to analyze all four zones. The system acquired and analyzed images at a rate of approximately $3 \mathrm{~Hz}$. The voltage was adjusted in $50 \mathrm{~V}$ increments to maintain the conditions for desirable spray modes. With the tip positioned approximately $5 \mathrm{~mm}$ from the ground plate, a stable spray was established and maintained at $1400 \mathrm{~V}$.

When the pump flow rate was increased to $2 \mu \mathrm{L} /$ min, an automated increase in the applied voltage was observed. As the flow rate increased, the spray mode distinctly changed from cone-jet to spindle, and generated distinct edges in zones three and four. The algorithm automatically raised the applied voltage by $50 \mathrm{~V}$ for each image acquired in the spindle mode. After approximately $30 \mathrm{~s}$ of acquisition, the voltage was raised to $2100 \mathrm{~V}$. The large droplets were no longer detected in zones three and four and the plume returned to the cone-jet or pulsed cone-jet spray mode.

A decrease in flow rate resulted in an automated decrease in operating voltage. As the flow rate was reduced to $100 \mathrm{~nL} / \mathrm{min}$, the single cone-jet transformed to the multi-jet spray mode. The algorithm automatically decreased the applied voltage by $50 \mathrm{~V}$ for each image frame where additional edges in zones one and two were detected. After approximately $4 \mathrm{~min}$, the flow rate stabilized. The operating voltage was reduced to $1600 \mathrm{~V}$, and the cone-jet or pulsed cone-jet spray mode returned.

To test system performance for gradient chromatography, the syringe pump was replaced with the split flow gradient LC system to yield a flow rate of $450 \pm$ $100 \mathrm{~nL} / \mathrm{min}$ and a $30 \mu \mathrm{m}$ emitter was mounted on the source. The gradient was initialized with an aqueous solution of $10 \%$ ACN increased to $90 \%$ ACN over a 10 min period. The composition was held at $90 \%$ for $2 \mathrm{~min}$ and then reduced to $10 \% \mathrm{ACN}$ for another $10 \mathrm{~min}$ gradient. Before the start of the gradient, the flow rate was allowed to equilibrate with $10 \%$ ACN. The computer control system was initialized and a pulsed cone-jet/cone-jet spray mode was automatically established at $2100 \mathrm{~V}$. As the mobile phase changed composition to a higher percentage of $\mathrm{ACN}$, the reduction in surface tension caused the multi-jet spray mode to transiently form (Figure 10b). The (pulsed) cone-jet-tomulti-jet spray mode transformation could form at any given point during the gradient. This transformation resulted in the detection of more than two distinct edges in zones one and two. With each resulting image, the applied voltage was automatically reduced by $50 \mathrm{~V}$. The voltage was reduced until the (pulsed) cone-jet mode was re-established. As the mobile phase composition changed, the spray resided in the (pulsed) conejet spray mode(s) for more than $90 \%$ of the time and occupied the multi-jet spray mode periodically for a limited number of image cycles. At the end of the first gradient $(90 \% \mathrm{ACN})$ a stable cone-jet spray mode was maintained at $1500 \mathrm{~V}$ for two min. As the gradient reversed back to $10 \% \mathrm{ACN}$, the spindle spray mode would periodically appear and the algorithm automatically raised the applied voltage in $50 \mathrm{~V}$ increments for each resulting image. At the end of the run, a pulsed cone-jet mode was obtained with the applied voltage ranging between 2200 to $2500 \mathrm{~V}$. The system was tested at different gradient conditions, and nearly identical performance was obtained with 3 to 30 min gradients.

Given the relatively low bandwidth $(3 \mathrm{~Hz})$ of the orthogonal system, control was occasionally lost for special cases when spray mode instabilities, such as spray mode hopping, were present on a similar timescale. Such events can result in feedback instability. Under such conditions, the system's spray mode determination may not represent the instantaneous, realtime mode at the emitter. For the above example, loss of spray could occur just after the spray start cycle when spraying $10 \%$ ACN. When using a $30 \mu \mathrm{m}$ emitter under these conditions, a naturally oscillating mode hop, between multi-spindle and micro-dripping spray modes, was occasionally present with an oscillation frequency of ca. $0.5 \mathrm{~Hz}$. If the control system acquired a multi-spindle image (indicating the applied voltage was too high) and the voltage was subsequently lowered at the instant when the dripping mode was present, the spray was lost altogether. Substituting a smaller, $15 \mu \mathrm{m}$ emitter eliminated this mode hopping behavior. Since mode hopping has been observed as a typically low frequency (approximately 0.1 to $1 \mathrm{~Hz}$ ) event, improved analysis bandwidth should reduce this tendency.

The automated orthogonal control system described in this study can be significantly enhanced in a number of ways. The present system offers poor discrimination between the stable and pulsed cone-jet modes because their reflected light images are so similar. This deficiency can be eliminated in two ways: Either by use of strobed light images in addition to reflected light, or by the integration of a frequency channel into the control computer. Frequency information provided by the laser/photodiode/oscilloscope system would prove particularly suitable. This hybrid image/frequency system would eliminate weak mode discrimination and provide identification of mixed mode and mode hopping conditions. System response could be improved (for 

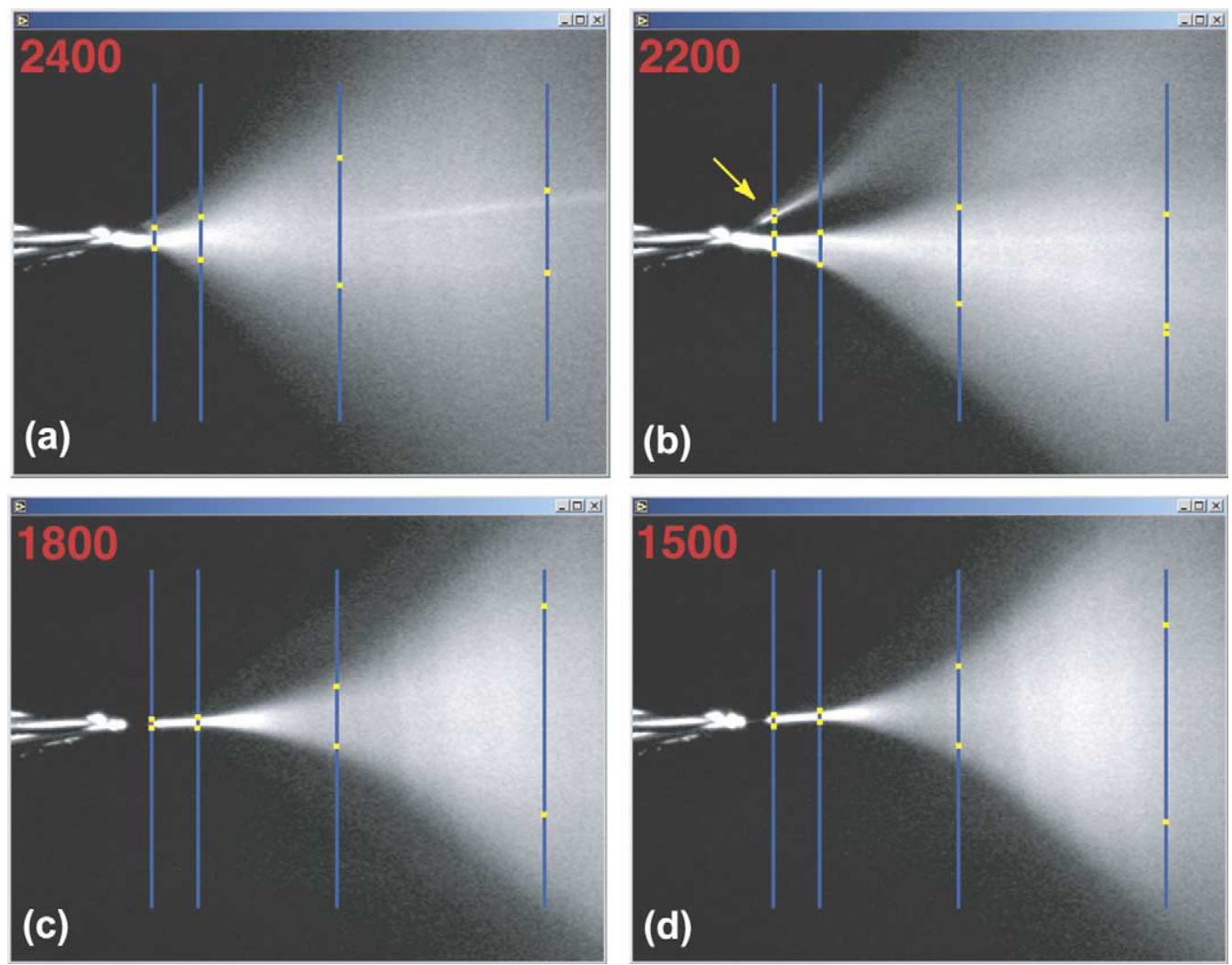

Figure 10. Single frame images obtained from the automated control gradient with a $30 \mu \mathrm{m}$ emitter pumped at ca. $450 \mathrm{~nL} / \mathrm{min}$. Applied voltage is indicated in the upper right hand image of each frame. (a) $10 \% \mathrm{ACN}$; (b) $20-30 \%$ ACN shows transient multiple streams that result from an over-voltage condition; (c) 20-30\% ACN after voltage correction, approximately 15 image cycles after (b); (d) at the end of the gradient, $90 \%$ ACN. The arrow notes additional edges detected in ROI zone 1 . Each blue vertical line represents the ROI zone. The yellow dots on each line show the location of detected edges (if any). The counter-electrode distance was $4.5 \mathrm{~mm}$.

repetitive chromatographic experiments) with the implementation of a learning algorithm that would run freely during the first gradient, storing a voltage profile for the experiment. Subsequent experiments would be based on the stored voltage profile, with the control system providing any necessary corrections for known or unknown changes in experimental conditions.

Repetitive experiments may also enable an approximation of results provided by the automated system. A suitable spray voltage could be determined manually, building a time course versus voltage relationship for each relevant section of the gradient. The applied voltage change(s) should provide reasonable control of spray mode, provided that the gradient delay from column-to-emitter is both stable and well characterized. However, an indeterminate spray mode that includes the possible loss of spray altogether would result from changes in mobile phase flow rate, gradient composition, column backpressure, emitter-source geometry, or pre-column volume.

\section{Conclusions}

A wide variety of spray modes have been observed for electrospray using image analysis with both re- flected and strobed light illumination. Unlike the well known Taylor cone-jet spray mode, many of these modes are pulsed and/or oscillatory and have routinely observed fundamental frequencies of $50 \mathrm{kHz}$ or more. Spray mode generation and control is very sensitive to the electric field strength surrounding the emitter and is commonly controlled through the applied spray potential. Based on these image observations, an automated orthogonal opto-electronic system capable of determination and control of specific spray modes has been developed. Through control of the applied potential, this system automatically initiates an ESI spray and maintains optimal spray conditions throughout an aqueous chromatographic gradient. The automated system can respond to changes in flow rate, mobile phase composition, or both simultaneously. Such a system requires no user intervention and affords the opportunity for extended, unattended analytical experiments at nanospray flow rates. The improvement of the orthogonal system, including the use of frequency information in the control algorithm along with its subsequent integration into a nanospray equipped mass spectrometer, is under development. 


\section{References}

1. Lee, M. S.; Kerns, E. H. LC/MS Applications in Drug Development. Mass Spectrom. Rev. 1999, 18, 187-279.

2. Patterson, S. D.; Aebersold, R. Mass Spectrometric Approaches for the Identification of Gel Separated Proteins. Electrophoresis 1995, 16, 1791-1814.

3. Shevchenko, A.; Jensen, O. N.; Podtelejnikov, A. V.; Sagliocco, F.; Wilm, M.; Vorm, O.; Mortensen, P.; Shevchenko, A.; Boucherie, H.; Mann, M. Linking Genome and Proteome by Mass Spectrometry: Large-Scale Identification of Yeast Proteins from Two Dimensional Gels. Proc. Natl. Acad. Sci. U.S.A. 1996, 93, 14440-14445.

4. Washburn, M. P.; Wolters, D.; Yates, J. R. Large-Scale Analysis of the Yeast Proteome by Multidimensional Protein Identification Technology. Nat. Biotechnol. 2001, 19, 242-247.

5. Cody, R. B. Electrospray Ionization Mass Spectrometry: History, Theory, Instrumentation. In Applied Electrospray Mass Spectrometry; Pramanik, B. N.; Ganguly, A. K.; Gross, M. L., Eds.; Marcel Dekker, Inc.: New York, 2002; pp 1-104.

6. Fenn, J. B.; Mann, M.; Meng, C. K.; Wong, S. F.; Whitehouse, C. M. Electrospray Ionization for Mass Spectrometry of Large Molecules. Science 1989, 246, 64-71.

7. Dole, M.; Mack, L. L.; Hines, R. L.; Mobley, R. C.; Ferguson, L. D.; Alice, M. B. Molecular Beams of Macroions. J. Chem. Phys. 1968, 49, 2240-2249.

8. Mack, L. L.; Kralik, P.; Rheude, A.; Dole, M. Molecular Beams of Macroions. II. J. Chem. Phys. 1970, 52, 4977-4986.

9. Covey, T. R.; Lee, E. D.; Henion, J. D. High-Speed Liquid Chromatography/Tandem Mass Spectrometry for the Determination of Drugs in Biological Samples. Anal. Chem. 1986, 58, 2453-2460.

10. Hail, M. E., Mylchreest, I. C. Electrospray Ion Source and Interface Apparatus and Method. Finnigan Corporation, Feb. 28, 1995, U.S.A. Patent 5393975.

11. Gale, D. C.; Smith, R. D. Small Volume and Low Flow-Rate Electrospray Ionization Mass Spectrometry of Aqueous Samples. Rapid Commun. Mass Spectrom. 1993, 7, 1017-1021.

12. Wilm, M. S.; Mann, M. Electrospray and Taylor-Cone Theory, Dole's Beam of Macromolecules at Last? Int. J. Mass Spectrom. Ion Processes 1994, 136, 167-180.

13. Emmett, M. R.; Caprioli, R. M. Micro-Electrospray Mass Spectrometry: Ultra-High-Sensitivity Analysis of Peptides and Proteins. J. Am. Soc. Mass Spectrom. 1994, 5, 605-613.

14. Valaskovic, G. A.; Kelleher, N. L.; Little, D. P.; Aaserud, D. J.; McLafferty, F. W. Attomole-Sensitivity Electrospray Source for Large-Molecule Mass Spectrometry. Anal. Chem. 1995, 67, 3802-3805.

15. Wilm, M. S.; Mann, M. Analytical Properties of the Nanoelectrospray Ion Source. Anal. Chem. 1995, 68, 1-8.

16. Geronmanos, S.; Freckleton, G.; Tempst, P. Tuning of an Electrospray Ionization Source for Maximum Peptide-Ion Transmission into a Mass Spectrometer. Anal. Chem. 2000, 72, 777-790.

17. Valaskovic, G. A.; Kelleher, N. L.; McLafferty, F. W. Attomole Protein Characterization by Capillary Electrophoresis-Mass Spectrometry. Science 1996, 273, 1199-1202.

18. Juraschek, R.; Dulcks, T.; Karas, M. Nanoelectrospray-More Than Just a Minimized-Flow Electrospray Ionization Source. J. Am. Soc. Mass Spectrom. 1999, 10, 300-308.

19. Schmidt, A.; Karas, M.; Dulcks, R. Effect of Different Flow Rates on Analyte Ion Signals in Nano-ESI MS, or: When Does ESI Turn into Nano-ESI? J. Am. Soc. Mass Spectrom. 2003, 14, 492-500.
20. Gangl, E. T.; Annan, A.; Spooner, N.; Vouros, P. Reduction of Signal Supression Effects in ESI-MS Using a Nanosplitting Device. Anal. Chem. 2001, 73, 5635-5644.

21. De la Mora, J. F.; Van Berkel, G. J.; Enke, C. G.; Cole, R. B.; Martiniz-Sanchez, M.; Fenn, J. B. Electrochemical Processes in Electrospray Ionization Mass Spectrometry. J. Mass Spectrom. 2000, 35, 939-952.

22. Cloupeau, M.; Prunet-Foch, B. Electrohyrdrodynamic Spraying Functioning Modes: A Critical Review. J. Aerosol Sci. 1994, 25, 1021-1036.

23. De Juan, L.; Fernandez De La Mora, J. Charge and Size Distributions of Electrospray Drops. J. Colloid and Interface Sci. 1997, 186, 280-293.

24. Enke, C. G. A Predictive Model for Matrix and Analyte Effects in Electrospray Ionization of Singly-Charged Ionic Analytes. Anal. Chem. 1997, 69, 4885-4893.

25. Cech, N. B.; Enke, C. G. Relating Electrospray Ionization Response to Nonpolar Character of Small Peptides. Anal. Chem. 2000, 72, 2717-2723.

26. Cech, N. B.; Enke, C. G. Effect of Affinity for Droplet Surfaces on the Fraction of Analyte Molecules Charged during Electrospray Droplet Formation. Anal. Chem. 2001, 73, 4632-4639.

27. Zeleny, J. The Electrical Discharge from Liquid Points, and a Hydrostatic Method of Measuring the Electric Intensity at Their Surfaces. Phys. Rev. 1914, 3, 69-91.

28. Zeleny, J. Instability of Electrified Liquid Surfaces. Phys. Rev. $1917,10,1-6$.

29. Jaworek, A.; Krupa, A. Classification of the Modes of EHD Spraying. J. Aerosol Sci. 1999, 30, 873-893.

30. Juraschek, R.; Schmidt, A.; Karas, M.; Rollgen, F. W. Dependence of Electrospray Ionization Efficiency on Axial Spray Modes. Adv. Mass Spectrom. 1998, 14, 1-15.

31. Olumee, Z.; Callahan, J. H.; Vertes, A. Droplet Dynamics Changes in Electrostatic Sprays of Methanol-Water Mixtures. J. Phys. Chem. 1998, 102, 9154-9160.

32. Tang, K.; Gomez, A. On the Structure of an Electrostatic Spray of Monodisperse Droplets. Phys. Fluids 1994, 6, 2317-2332.

33. Gomez, A.; Tang, K. Charge and Fission of Droplets in Electrostatic Sprays. Phys. Fluids 1994, 6, 404-414.

34. Juraschek, R.; Rollgen, F. W. Pulsation Phenomena During Electrospray Ionization. Int. J. Mass Spectrom. 1998, 177, 1-15.

35. Wei, J.; Shui, W.; Zhou, F.; Lu, Y.; Chen, K.; Xu, G.; Yang, P. Naturally and Externally Pulsed Electrospray. Mass Spectrom. Rev. 2002, 21, 148-162.

36. Taylor, G. Disintegration of Water Drops in an Electric Field. Pro. Royal Soc. A 1964, A280, 383-397.

37. Tang, K.; Gomez, A. Generation of Monodisperse Water Droplets from Electrosprays in a Corona-Assisted Cone-Jet Mode. J. Colloid and Interface Sci. 1995, 175, 326-332.

38. Tomer, K. B.; Moseley, M. A.; Deterding, L. J.; Parker, C. E. Capillary Liquid Chromatography/Mass Spectrometry. Mass Spectrom. Rev. 1994, 13, 431-457.

39. Martin, S. E.; Shabanowitz, J.; Hunt, D. F.; Marto, J. B. Subfemtomole MS and MS/MS Peptide Sequence Analysis Using Nano-HPLC Micro-ESI Fourier Transform Ion Cyclotron Resonance Mass Spectrometry. Anal. Chem. 2000, 72, $4266-4274$.

40. Inoue, S.; Spring, K. R. Video Microscopy: The Fundamentals; 2nd ed; Plenum Press: New York, 1997, p 200.

41. Snyder, L. R.; Kirkland, J. J.; Glajch, J. L. Practical HPLC Method Development; 2nd ed; John Wiley and Sons, Inc.: New York, 1997, pp 721-728.

42. Jahne, B. Digital Image Processing; Springer-Verlag: Berlin, 1991, p 134. 